detect meaningful treatment effects. It would be interesting to discuss whose assessment is most accurate: that of the experts of care or that of the experts of their own illness? Second, as in other trials of cholinesterase inhibitors, there was clearly an effect of the intervention itself, as evidenced by a slight improvement in all groups. This underlines the importance of involving patients and their caregivers and having them feel that they are being cared for. Finally, it is unclear why, after 2 months of galantamine use, patients who received the drug for the first time during the open-label phase did not improve in the same way as patients who received it for the first time during the placebo-controlled phase. One explanation may be that the open-label data are not reliable owing to selection bias.

In conclusion, although Rockwood and colleagues do not present convincing evidence of the efficacy of galantamine in the treatment of mild to moderate Alzheimer's disease, they do introduce an interesting instrument for dementia research.
Hanna Kaduszkiewicz is with the Department of Primary Medical Care, Center of Psychosocial Medicine, University Medical Center HamburgEppendorf, Hamburg, Germany.

Competing interests: None declared.

\section{REFERENCES}

I. Birks J. Cholinesterase inhibitors for Alzheimer's disease [Cochrane review]. In: The Cochrane Library; Issue I, 2006. Oxford: Update Software

2. Schneider LS. AD2000: Donepezil in Alzheimer's disease. Lancet 2004;363:2100-I.

3. Kaduszkiewicz H, Zimmermann T, Beck-Bornholdt HP, et al. Cholinesterase inhibitors for patients with Alzheimer's disease: systematic review of randomised clinical trials. BMJ 2005;331:32I-7.

4. Rockwood K, Fay S, Song X, et al. Attainment of treatment goals by people with Alzheimer's disease receiving galantamine: a randomized controlled trial. CMAJ 2006;174(8):I099-I05.

Correspondence to: Dr. Hanna Kaduszkiewicz, Department of Primary Medical Care, Center of Psychosocial Medicine, University Medical Center Hamburg-Eppendorf, Martinistra 52, 20246 Hamburg, Germany; fax +49 (0) 4042803368 ; kaduszki@uke.uni-hamburg.de

\title{
The economic case for planned cesarean section for breech presentation at term
}

\author{
Jane Henderson, Stavros Petrou
}

$\infty \quad$ See related article page $\mathrm{I}$ Iog

$\mathrm{B}$ reech presentation occurs in $3 \%-4 \%$ of deliveries. The optimal method for delivering these babies has been a controversial issue in obstetrics. The Term Breech Trial compared the efficacy of planned caesarean section with that of planned vaginal delivery for breech presentation at term. ${ }^{1}$ The combined outcome of perinatal or neonatal death and serious neonatal morbidity was significantly and substantially lower with planned cesarean section than with planned vaginal delivery (I.6\% v. 5.0\%; relative risk $0.33,95 \%$ confidence interval 0.9 to I0.56). The paper by Roberto Palencia and colleagues published in this issue of the Journal ${ }^{2}$ presents a detailed study of the costs incurred by the 2 arms of the Term Breech Trial, which were analyzed by intention to treat.

The investigators found that costs were lower in the group allocated to planned cesarean section than in the group allocated to vaginal delivery ( $\$ 7 \mathrm{I} 65 \mathrm{v}$. $\$ 8042$ [all costs in 2002 Canadian dollars]; average difference $-\$ 877,95 \%$ credible interval $-\$ 1286$ to $-\$ 473$ ), which makes this option both more efficacious and less costly. A policy of planned cesarean section for breech presentation can therefore be viewed as "dominant" in broader cost-effectiveness terms. ${ }^{3}$

The difference in costs between the 2 groups was largely related to the relatively high physician fees for carrying out a vaginal breech delivery as well as to the higher costs of epidural analgesia, in-hospital costs of labour and delivery and costs of neonatal intermediate and intensive care. It is worth noting that $43 \%$ of women allocated to vaginal delivery subsequently delivered by cesarean section, $36 \%$ after labour began. Costs incurred by this group therefore included both the higher labour costs as well as the operating theatre costs associated with a cesarean section. Because the analysis was, correctly, by intention to treat, costs are not presented separately for those women who planned to and did deliver vaginally. Therefore, comparisons with most other studies in this area are problematic. ${ }^{4}$

Costs incurred from the time of randomization up to 6 weeks postnatally and related to both the mother and infant were included. Although the trial was carried out in 26 countries, the costing study was limited to the $\mathrm{I} 6$ countries with rates of perinatal death of 20/1000 or less to increase generalizability to the Canadian health care system. Although resource utilization data were included from all of these 16 countries, unit costs were taken from only 7 Canadian hospitals, which were selected on the basis of their accessibility and the quality of their financial information. Although the 7 centres were a mixture of teaching and community hospitals, we do not know how representative they are of the trial participating centres, and we know still less of the generality of obstetric units. Even among the 7 centres, there was wide vari- 
ability in the reported unit costs. This was most marked in the hourly cost of an operating theatre, which ranged from $\$ 150$ to $\$ 1493$, and there was a 2-fold difference in the hourly cost of most facilities. Similarly, physician fees for services also commonly exhibited a $2-3$-fold variation. Crucially, the daytime fee for vaginal breech delivery ranged from $\$ 370$ to $\$ 7$ I 2 . All of this suggests considerable uncertainty around the costs of the key antenatal, intrapartum and neonatal resource in-

\section{Planned cesarean confers} better perinatal and neonatal outcomes and is less costly than planned vaginal birth.

puts. Despite this high level of uncertainty, in the face of the study's findings of clinical effectiveness, economic techniques such as cost-effectiveness acceptability curves and net benefit statistics (not performed in this study) are still likely to provide a strong economic case for planned cesarean for breech presentation at term. ${ }^{3}$

In countries outside North America, physicians are often salaried staff, paid according to their grade and hours worked rather than per procedure. Generalizability to these types of health care systems may therefore be questionable. It is likely that cost differences would be smaller in health care systems where staff are salaried.

The economic analysis was conducted from a Ministry of Health or third-party-payer perspective. A broader perspective would have included the costs of additional care of and support for new mothers at home, which is often provided by relatives and friends during the postnatal period. These costs may include both direct costs in terms of travel and leisure time forgone and indirect costs if time is taken from work to provide that care. In a systematic review of economic studies of different modes of delivery, ${ }^{4}$ the viewpoint of almost all the studies was limited to that of the health care provider, was generally short term and rarely went beyond the postnatal period.

As with the trial itself, the economic analysis was limited to the time between randomization and 6 weeks postpartum. A longer time frame would probably have increased the cost differences between the comparator groups because of the costly care of babies who remain in neonatal intensive and intermediate care beyond 6 weeks postpartum. Similarly, utilization of community health care would generally be higher with these babies once they are discharged from hospital. ${ }^{5}$ To counterbalance this, the resources required to care for future pregnancies are likely to be greater following a cesarean than following a vaginal delivery. ${ }^{6}$
Palencia and colleagues note that, despite the benefits to the infant, the risk of adverse maternal outcomes associated with cesarean section may affect women's preferences for this form of care. Further research in this area should consider eliciting women's preferences for planned cesarean and planned vaginal birth using economic techniques such as multi-attribute utility measures, the willingness-to-pay approach and stated preference discrete choice modelling. ${ }^{7}$

In conclusion, this detailed analysis of the costs associated with the delivery of a baby in breech presentation at term has demonstrated that planned cesarean, as well as conferring better perinatal and neonatal outcomes, is less costly than planned vaginal birth. The study results make an important contribution to the policy debate in this area.

Jane Henderson and Stavros Petrou are with the National Perinatal Epidemiology Unit, University of Oxford, England.

Competing interests: None declared.

Contributors: Both of the authors made substantial contributions to the conception and drafting of the paper, revised it critically for important intellectual content and gave final approval of the version to be published.

\section{REFERENCES}

I. Hannah ME, Hannah WJ, Hewson SA, et al.; Term Breech Trial Collaborative Group. Planned caesarean section versus planned vaginal birth for breech presentation at term: a randomised multicentre trial. Lancet 2000;356:1375-83

2. Palencia R, Gafni A, Hannah ME, et al. The costs of planned cesarean versus planned vaginal birth in the Term Breech Trial. CMAJ 2006;174(8):I109-I3.

3. Drummond MF, Sculpher MJ, Torrance GW, et al. Methods for the economic evaluation of health care. Oxford University Press: Oxford;2005.

4. Henderson J, McCandlish R, Kumiega L, et al. Systematic review of economic aspects of alternative modes of delivery. Br J Obstet Gynaecol 200I;I08:I49-57.

5. Petrou S, Mehta Z, Hockley C, et al. The impact of preterm birth on hospital inpatient admissions and costs during the first five years of life. Pediatrics 2003; II2:I290-7.

6. Bewley S. The unfacts of "request" caesarean section. Br J Obstet Gynaecol 2002; I09:597-605.

7. Petrou S, Henderson J. Preference-based approaches to measuring the benefits of perinatal care. Birth 2003;30:217-26.

Correspondence to: Ms. Jane Henderson, National Perinatal Epidemiology Unit, Old Road Campus, Oxford oX 3 TLF UK; fax +44-I865-227002; jane.henderson@npeu.ox.ac.uk 